\title{
Correlations between Cognitive Performance and Readiness to Change in Cocaine/Crack Users*
}

\section{Correlaciones entre la performance cognitiva y la prontitud al cambio en usuarios de cocaína/crack}

\author{
Viviane Samoel Rodrigues ${ }^{\mathrm{a}}$ \\ Pontifícia Universidade Católica do Rio Grande do Sul \\ (PUCRS), Brasil \\ ORCID: http://orcid.org/0000-0002-0854-3953 \\ Letícia Ribeiro \\ Pacific University, Estados Unidos \\ Letícia Arruda Rodrigues \\ Pontifícia Universidade Católica do Rio Grande do Sul \\ (PUCRS), Brasil \\ TATIANA Quarti Irigaray \\ Pontifícia Universidade Católica do Rio Grande do Sul \\ (PUCRS), Brasil \\ Fernanda de Almeida Ribeiro \\ Pontifícia Universidade Católica do Rio Grande do Sul \\ (PUCRS), Brasil \\ Margareth da Silva Oliveira \\ Pontifícia Universidade Católica do Rio Grande do Sul \\ (PUCRS), Brasil
}

\begin{tabular}{l}
\hline a Correspondance author. \\
letypsicologa@gmail.com \\
Para citar este artículo: Rodrigues, V., Ribeiro, L., \\
Arruda, L., Quarti, T. De Almeida, F., \& Da Silva, M. \\
(2017). Correlations between Cognitive Performance \\
and Readiness to Change in Cocaine/Crack Users. \\
Universitas Psychologica, 16(2). https://doi.org/10.1 \\
1144/Javeriana.upsy16-2.ccpr
\end{tabular}

Universitas Psychologica, 16(2). https://doi.org/10.1

\begin{abstract}
A substance user's readiness to change is fundamental to the success of psychological interventions and treatments. Preserving neuropsychological functions is an integral part of moving towards readiness, yet few studies have evaluated the influence of cognition on a user's motivation to change. Therefore, this paper aimed to verify the possible correlations between a user's cognitive deficits and readiness to change through examining cocaine/crack users. This study analyzed a sample of 113 chronic cocaine/crack users' performances on the WCST and WAIS-III subtests, the URICA, and the Readiness to Change Ruler. The results showed significant correlations between the presence of cognitive deficits and lower levels of motivation to change. Multiple regression analyses revealed the influence of cognitive test performance on the increase of readiness to change among the participants, suggesting a direct relation between the preservation of neuropsychological functions and a stronger willingness to change in cocaine/crack users.

Keywords
\end{abstract}

cocaine; cognition; crack; neuropsychological functions; readiness to change

\section{RESUMEN}

La prontitud al cambio es un factor clave en el éxito de las intervenciones en los usuarios de drogas. Parte de este proceso está relacionado con 
la preservación de las funciones neuropsicológicas. Sin embargo, pocos estudios se han centrado en la influencia de estos en los procesos motivacionales. Este estudio examinó las asociaciones entre los déficits cognitivos y prontitud para el cambio en 113 usuarios de cocaína/crack, a los que se les aplicó el WCST, sub-tests del WAIS-III, la URICA y la Regla de prontitud para el cambio. Encontramos una correlación significativa entre los déficits cognitivos y menores grados de motivación. Tambien eran encontrados niveles de influencia del rendimiento en tests cognitivos en el aumento de la prontitud al cambio, lo que sugiere una relación directa entre la preservación de las funciones neuropsicológicas y una major prontitud para el cambio en los usuarios de cocaína/crack.

Palabrasclave

cocaína; crack; cognición; funciones neuropsicológicas; prontitud para el cambio

\section{Introduction}

Alongside Brazil, where this study was carried out, many countries worldwide consider the use of cocaine/crack a public health issue (Viola et al., 2012; Rodrigues, Horta, Szupszynski, Souza, \& Oliveira, 2013; Abdalla et al., 2014). Data about adherence to treatment reveals that about $50 \%$ of cocaine/crack users seek for treatment, the index of relapses, however, reaches 80\% (Ratnasingham, Cairney, Rehm, Manson, \& Kurdyak, 2012). Those indexes highlight the need for a deeper understanding of factors involved in treatment adherence and success among these populations. Studies have been reporting the importance of both motivation to change and the cognitive status in treatment outcomes among substance users (Compton, Thomas, Stinson, \& Grant, 2007; Corsi, Kwiatkowski, \& Booth, 2007; Henderson, Saules, \& Galen, 2004; Longshore \& Teruya, 2006). These data suggests possible interactions between the two variables, but very few studies have addressed this question until the date.

According to the Transtheoretical Model of Change (Prochaska \& DiClemente, 1982), motivation to change is a complex process involving four well-defined stages: precontemplation (PC), contemplation (CO), action (AC), and maintenance (MA). PC is the initial stage in which the person is not aware of the problem, not expressing interest in quitting the addictive behavior. In $\mathrm{CO}$, the individual is ambivalent and slowly starts thinking about the damages the substance use is causing to him/ herself and others. The third stage, AC, is when there is full awareness of the problem and the person makes real efforts to change. Lastly, in MA, the individual takes proper steps toward changing his/her behavior as whole, targeting the prevention of relapses (DiClemente, Schlundt, $\&$ Gemmell, 2004). The path from PC to MA requires the ability to recognize the problem and an active engagement in the process. The inability too accurately track situations that trigger substance use or failures in behavioral selfcontrol when facing cravings play a fundamental role in successful behavioral changes. Tracking, planning, and the ability of self-monitoring and control are behaviors dependent on the preservation of neuropsychological functions such as attention, memory, inhibitory control, decision-making, and problem-solving. In that sense, substance user's cognitive status is a relevant issue when considering the changing process involved in treatments.

It is largely known that cocaine/crack users present important cognitive deficits (CF) due to the chronic substance use (Berry et al., 1993; Spronk, et. al, 2013). Studies report that those losses are linked to physiological brain damage, such as morphological alterations in dopaminergic synapses, and a reduction of metabolic activity and cerebral volume, especially on the orbitofrontal and dorsolateral portions of the prefrontal cortex (Viola et al., 2012; Cunha Bechara, de Andrade, \& Nicastri, 2010; Boys, Marsden, \& Strang, 2001). These physiological alterations, mostly on the orbitofrontal and dorsolateral portions of the prefrontal cortex, explain cocaine/crack users' difficulties with attention, working memory, and processing speed as well as higher order executive functioning (EF) (Cunha et al., 2010; Kjome et al., 2010; Severston, von Thomsen, Hedden, \& Latimer, 2010; Viola et al., 2012).

Cognitive deficits and treatment outcomes have been extensively explored in the literature (Aharonovich, Amrhein, Bisaga, Nunes, \& Hasin, 2008; Ahmadi et al., 2009; Fernandez- 
Serrano, Perez-Garcia, Perales, \& VerdejoGarcia, 2010). Only a few studies, however, have explored the correlations between CF and the motivational status of substance users in treatment. In a study of alcoholics, motivation to change where correlated to intellectual functioning, memory, and abstraction (Blume, Schmaling, \& Marlatt, 2005). Results revealed that low verbal and delayed memory recall were associated with the PC stage. The study also found that reduced alcohol consumption, at the three-month follow-up, resulted in user's increased capacity to maintain attention. The result suggests a correlation between the improved cognitive abilities and the $\mathrm{AC}$ and MA changing stages. Another study (Rigoni, Oliveira, Susin, Sayago, \& Feldens, 2009), which aimed to assess the correlations between readiness to change and cognitive status among alcoholics, found that the less motivated to change exhibited a poorer performance on the Wisconsin Card Sorting Test (WCST) when compared to the more motivated participants. The poor performance was demonstrated by their reduced number of categories completed (CC), greater failure in set maintenance (FSM), and a higher number of perseverative errors (PE). Using a sample of cocaine and heroin users, Severtson, von Thomsen, Hedden and Latimer (2010) explored the association between the readiness to start treatment and performance on the WCST. They observed that poorer performance on the WCST was associated with lower recognition of the substance use as a problem. This result reinforces the role of cognition status in the willingness to change among substance users.

Many studies showed that motivation and cognitive status predict treatment success (Corsi, Kwiatkowski, \& Booth, 2007; Henderson, Saules, \& Galen, 2004; Longshore \& Teruya, 2006). However, few have examined the relationship between cognitive factors and their association with motivation to change. Considering readiness to change as a fundamental feature in intervention success, and that cognitive functioning plays a role in this process, the present study verified the correlations between cognitive performance and readiness to change in cocaine/crack users.

\section{Method}

\section{Participants}

Participants were recruited from drug treatment facilities in the city of Porto Alegre, RS, Brazil. The sample was retrieved from a larger study that evaluated the effectiveness of a treatment intervention based on the TTM and Motivational Interviewing. The study was conducted on facilities that held an educational partnership with the Pontificia Universidade Catolica do Rio Grande do Sul (PUCRS), being advertised among the interns. Those who were willing to participate in the study were informed of its objectives and assured that all data would be de-identified. Participants consented participation by signing an informed consent form. This study was approved by the Research Ethics Committee of PUCRS, protocol number $11 / 05322$.

One hundred and thirteen individuals of both genders, between 18 and 57 years old, participated in the study. All individuals were interns and had abstained from substance use for at least seven consecutive days by the time of the evaluation. In this sample, $40.7 \%$ were cocaine users, $21.2 \%$ were crack users, and $38.1 \%$ used both cocaine and crack.

\section{Instruments}

Demographic data was collected by a socialdemographic questionnaire and the clinical status of the sample was stablished by a semi-structured clinical interview based on the DSM-IV-TR (2004). Cognitive performance was assessed by the Wisconsin Card Sorting Test (WCST), the Rey Complex Figure Test (RCFT), and the cognitive screening subtests of the Wechsler Adult Intelligence Scale (WAIS-III). 


\section{Cognitive screening}

The WAIS-III cognitive screening subtests (Wechsler, 1997) include vocabulary (VOC), digit span (DS), block design (BD), and digit symbol-coding tests (SC). The VOC test assesses verbal knowledge and long-term memory, being a good measure of premorbid cognition. The DS measures sustained attention, inhibitory control, and working memory, while BD assesses planning and visual-motor organization. The SC measures visual reproduction, psychomotor ability, and processing speed (Cunha, Nicastri, Gomes, Moino, \& Peluso, 2004).

\section{Working Memory and Visual-spatial skills}

The RCFT requires the copy and further memory drawing of a complex geometrical figure in three moments: immediately, three minutes, and 30 minutes after the copy. We used only the copy and immediate memory trials in the study to measure visual perception and immediate memory damages (Oliveira, 2010).

\section{Cognitive Flexibility}

The Wisconsin Card Sorting Test was used to track EF deficits such as mental flexibility, categorization, sequencing, and problem-solving abilities (Cunha et al., 2004). The 120 cards of the WCST was administered and corrected manually.

\section{Self-reported measures of motivation}

Participants' readiness to change was assessed by both the URICA (University of Rhode Island Change Assessment - McConnaughy, Prochaska, \& Velicer, 1983) and the Readiness to Change Ruler (RCR). Developed to be a quick and simple measure, the RCR consists of an idiographic measure in which individuals should specify their motivational state towards change on a self-report, 10-item Likert scale (Velasquez, Maurer, Crouch, \& DiClemente, 2001). The
URICA is a 24-item, self-report Likert scale developed to measure the motivational stage through four subscales: PC, CO, AC, and MA. The Brazilian version, used in this study, showed adequate total internal consistency $(\alpha=0.65$; Szupszynski \& Oliveira, 2008).

\section{Procedures for data collection}

Data collection was performed within an overall period of 6 months throughout the year 2012 . Assessments were given by research assistants of PUCRS trained to give and correct the cognitive tests and self-report measures. Training and supervision of the study staff were performed by a Psychologist specialized in both cognitive assessments and drug abuse treatment.

Assessment sessions were performed individually by the research assistants within the facilities. Sessions began with the demographic and diagnostic interview, followed by the selfreport and the cognitive assessments. The assessments were completed in single sessions of $60-90$ minutes of duration.

\section{Data analysis}

Continuous variables were described using average, standard deviation, median, interquartile range, and range of variation. Depending on variable characteristics, we applied either Pearson's or Spearman's coefficient correlations to assess the relationship between cognitive performance and the scores obtained on the URICA and the RCR scales. To verify the influence of cognitive performance on motivational stages, we performed a multiple linear regression analysis selecting variables systematically. All analyses were conducted with the use of the software SPPS version 18. The adopted significance level was $5 \%(\mathrm{p} \leq 0.05)$. 


\section{Results}

\section{Sample characterization}

The sample was composed of young adults, mostly single $(69.6 \%)$, with an average age of 29.2 years (SD 8.06) (see Table 1 for full information). Regarding education, $33.9 \%$ did not finish elementary school, and only $29.5 \%$ finished high school. From the sample, $40.7 \%$ used crack only, and $21.2 \%$ only used cocaine, whereas $38.1 \%$ used both. Participants were abstinent 20.5 days on average.

\section{TABLE 1}

Socio-demographic data for sample group $(n=113)$

\begin{tabular}{lccc}
\hline Socio-demographic characteristics & $\begin{array}{c}\text { Total subjects } \\
(\mathbf{n}=\mathbf{1 1 3})\end{array}$ & $\%$ & Mean \pm SD \\
\hline GENDER & 107 & 94.7 & \\
$\quad$ Male & 6 & 5.3 & $29.2 \pm 8.1$ \\
$\quad$ Female & & & \\
AGE (years) & & & \\
EDUCATION & 38 & 33.9 & \\
$\quad$ Did not finish elementary school & 39 & 34.8 & \\
$\quad$ Finished elementary school & 33 & 29.5 & \\
$\quad$ Finished high school & 2 & 1.8 & $9 \pm 3.1$ \\
$\quad$ Finished higher education & & & $14(5-60)$ \\
YEARS OF EDUCATION & & & $20.5(7.8-65)$ \\
HOSPITALIZATION TIME (days) & & & \\
CURRENT ABSTINENCE TIME (days) & & 40.7 & \\
ABUSED SUBSTANCE/DRUG & 46 & 21.2 & \\
$\quad$ Crack only & 24 & & \\
$\quad$ Cocaine only & & & \\
$\quad$ Crack + Cocaine & 43 & & \\
&
\end{tabular}

Source: own work.

Subjects' performance in cognitive and motivational screening

Table 2 shows the participants' scores on the URICA and on the RCR, as well as their performance on the cognitive tests. Regarding motivation using the RCR, the sample showed moderate motivational level, with self-reported scores ranging from 5 to 9 with an average of 7.3 $(\mathrm{SD} \pm 2.4)$. Motivational stages assessed by the URICA revealed that $33.6 \%$ were in PC, $27.4 \%$ in $\mathrm{AC}$, and $38.9 \%$ in $\mathrm{MA}$, indicating a large range of motivation to change within the sample.

The WAIS-III subtests scaled scores were calculated and interpreted according to the proper age and educational level of participants. The sample presented overall low average scores on the VOC, BD, and DS tests, suggesting difficulties in long-term memory, inhibitory control, planning, and visual-motor skills. Scores on SC were classified within the low range (borderline), indicating major damages in working memory and processing speed in the sample.

\section{TABLE 2}

Descriptive analysis of the RCR, the URICA, the WAIS subtests, WCST, and RCFT $(n=113)$

\begin{tabular}{|c|c|c|c|}
\hline Scores & Mean \pm SD & Median (P25 - P75) & Min to Max \\
\hline Readiness ruler & $7.3 \pm 2.4$ & $7(6$ to 9.5$)$ & 1 to 10 \\
\hline \multicolumn{4}{|l|}{ URICA - weighted T-score } \\
\hline Precontemplation & $52.4 \pm 8.2$ & $50(45$ to 60$)$ & 35 to 70 \\
\hline Contemplation & $44.2 \pm 6.7$ & $45(40$ to 45$)$ & 25 to 60 \\
\hline Action & $50.4 \pm 7.8$ & $50(45$ to 55$)$ & 25 to 60 \\
\hline Maintenance & $52.1 \pm 5.9$ & $50(50$ to 55$)$ & 30 to 60 \\
\hline \multicolumn{4}{|l|}{ WAIS tests } \\
\hline Vocabulary & $6.7 \pm 2.1$ & $7(5$ to 8$)$ & 2 to 11 \\
\hline Block design & $7.5 \pm 2.8$ & 7 (6 to 9$)$ & 2 to 19 \\
\hline Digit symbol-coding & $4.8 \pm 2.3$ & 4 (3 to 6$)$ & 1 to 13 \\
\hline Digit span & $5.8 \pm 2$ & $5(4$ to 7$)$ & 3 to 11 \\
\hline \multicolumn{4}{|l|}{ WISCONSIN test } \\
\hline Completed categories & $3.3 \pm 2$ & $3(2$ to 6$)$ & 0 to 6 \\
\hline Total number of errors & $49.1 \pm 28.9$ & $54(24.5$ to 72.5$)$ & 0 to 100 \\
\hline Persevering errors & $31.2 \pm 19.8$ & 27 (16.5 to 39.5$)$ & 3 to 94 \\
\hline Non-persevering errors & $23.3 \pm 14$ & 21 (13 to 33) & 2 to 71 \\
\hline $\begin{array}{l}\text { Trials to accomplish the } 1^{\text {st }} \\
\text { category }\end{array}$ & $32.9 \pm 36.6$ & 14 (11 to 37 ) & 10 to 129 \\
\hline$\%$ of answers of conceptual level & $49.8 \pm 21$ & 53 (35 to 66 ) & 3 to 94 \\
\hline Failure in set maintenance & $1.1 \pm 1.4$ & 1 (0 to 2$)$ & 0 to 7 \\
\hline Learning how to learn & $-5.6 \pm 9.6$ & $-1.6(-9.7$ to 0$)$ & -36.2 to 19.2 \\
\hline \multicolumn{4}{|l|}{ REY Complex Figure } \\
\hline Copy & $28.5 \pm 6.3$ & 30 (26.9 to 33) & 8 to 36 \\
\hline Memory & $12.1 \pm 6.6$ & $11.3(7.1$ to 17.5$)$ & 0 to 30 \\
\hline \multicolumn{4}{|c|}{$\begin{array}{l}\text { Note: WAIS-III scaled scores average } \\
=7 \text { (SD } \pm 6.3) \text {. RCFT average scores } \\
\text { (in points) for copy }=33.3 \text { and memory } \\
\text { reproduction }=18.8 \text { (Oliveira, 2010). } \\
\text { Source: own work. }\end{array}$} \\
\hline
\end{tabular}

On the RCFT, participants achieved an average of 28.5 points $(\mathrm{SD} \pm 6.3)$ in the copy, and 12.1 (SD \pm 6.6$)$ in the memory reproduction trial, being classified as low average (Oliveira, 2010). As only the copy and immediate memory trials were administered, the results yield deficits in visual perception and planning, as well as in attention and working memory. On the WCST, the majority of the sample failed in completing the six categories, presenting a large number of errors (see Table 2). Specifically, participants showed a high index of perseverative errors (PE) (31.2 \pm 19.8$)$, evidencing difficulties in tracking rules change indicating a low capacity for behavioral planning based on environmental feedback. 
Correlations between cognitive performance and motivational stages

Table 3 shows the correlations between the URICA, RCR, and cognitive performance. Although weak, we found a significant negative correlation between the number of $\mathrm{PE}$ on the WCST, and the motivational stages of $\mathrm{CO}\left(\mathrm{r}_{\mathrm{s}}=\right.$ $-0.192, \mathrm{p}<0.01)$ and $\mathrm{AC}\left(\mathrm{r}_{\mathrm{s}}=-.271, \mathrm{p}<0.05\right)$, which indicates that fewer $\mathrm{PE}$ is linked to higher levels of motivation to change. The same significant negative association was found, at a moderate level, between the PE and the score on the RCR $\left(r_{s}=-0.357, p<0.001\right)$. These results suggest an association between lower indexes of $\mathrm{PE}$ and higher readiness to change.

We found positive significant correlations between the RCR and scores on the VOC $(\mathrm{r}=-0.381, \mathrm{p}<0.001)$ and $\mathrm{BD}$ subtests $(\mathrm{r}=$ $0.295, \mathrm{p}<0.01$ ) of the WAIS, as well as on the completed categories $\left(r_{s}=0.201, p<0.05\right)$, learning how to learn $\left(r_{s}=0.21, p<0.05\right)$, and failure in set maintenance indexes $\left(\mathrm{r}_{\mathrm{s}}\right.$ $=0.187, p<0.05)$ of the WCST. Although such correlations are weak (Callegari-Jacques, 2005), these data reinforce the idea of a greater readiness to change being related to better cognitive performances.

No significant correlations were found between the RCFT and the URICA or the RCR.
TABLE 3

Relationship between the RCR and the URICA with cognitive test performance

\begin{tabular}{|c|c|c|c|c|c|}
\hline Scores & Ruler (RCR) & URICAPC & URICACO & URICA AC & URICA MA \\
\hline \multicolumn{6}{|l|}{ WAIS - weighted ${ }^{\mathrm{a}}$} \\
\hline Vocabulary & $0.266^{* * *}$ & $-0.381 * * *$ & 0.128 & 0.18 & 0.141 \\
\hline Block design & $0.295^{* *}$ & -0.113 & 0.06 & 0.068 & 0.037 \\
\hline Digit symbol-coding & 0.11 & $-0.336 * * *$ & -0.108 & -0.039 & 0 \\
\hline Digit span & 0.016 & -0.098 & 0.027 & 0.114 & 0.126 \\
\hline \multicolumn{6}{|l|}{ WISCONSIN $^{b}$} \\
\hline Completed categories & $0.201^{*}$ & -0.116 & 0.068 & 0.058 & 0.042 \\
\hline Total number of errors & -0.063 & 0.147 & -0.029 & 0.004 & 0.007 \\
\hline Perseverative errors & $-0.357^{* * * *}$ & 0.168 & $-0.192^{*}$ & $-0.271^{* *}$ & -0.129 \\
\hline $\begin{array}{l}\text { Non-perseverative } \\
\text { errors }\end{array}$ & 0.077 & 0.085 & 0.098 & .0134 & -0.085 \\
\hline $\begin{array}{l}\text { Trials to complete the } \\
1^{\text {st }} \text { category }\end{array}$ & -0.102 & 0.114 & -0.108 & 0.009 & 0.035 \\
\hline $\begin{array}{l}\% \text { of conceptual level } \\
\text { answers }\end{array}$ & 0.081 & -0.133 & 0.182 & 0.066 & 0.031 \\
\hline $\begin{array}{l}\text { Failure in set } \\
\text { maintenance }\end{array}$ & -0.027 & 0.104 & $0.187^{*}$ & 0.096 & -0.128 \\
\hline Learning how to learn & $0.21^{*}$ & -0.13 & 0.023 & 0.118 & 0.181 \\
\hline \multicolumn{6}{|l|}{$\mathrm{REY}^{\mathrm{a}}$} \\
\hline Copy & 0.063 & -0.023 & 0.083 & 0.138 & -0.044 \\
\hline Memory & 0.166 & -0.046 & -0.007 & 0.103 & 0.088 \\
\hline
\end{tabular}

Multiple linear regressions (step by step model) verified the influence of each of the cognitive performance variables on the RCR and the URICA subscales (Table 4). Results showed that the performance on PE had the greater influence $\left(10.7 \%, \mathrm{f}^{2}=0.12\right)$ in predicting the readiness to change by the RCR, followed by $\operatorname{VOC}\left(6.2 \%, \mathrm{f}^{2}=0.06\right)$ and the LHL index $\left(3.8 \%, f^{2}=0.03\right)$ for the WCST. Regarding the URICA motivational stages, we found that VOC $\left(13.8 \%, \mathrm{f}^{2}=0.16\right)$ and SC scores $(11.4 \%$, $\left.\mathrm{f}^{2}=0.13\right)$ significantly predicted the PC state. The amount of PE significantly predicted $\mathrm{CO}$ stage in $3.7 \%\left(\mathrm{f}^{2}=0.03\right)$. Despite the small effect sizes of the prediction of the cognitive performance over the motivational stages, these findings indicate that cognition plays a significant role in the explained variance of readiness to change, acknowledging the importance of cognitive status and its influence over motivation to change among crack and cocaine users. 
TABLE 4

Multilinear regressions with cognitive variables and RCR and URICA subscales

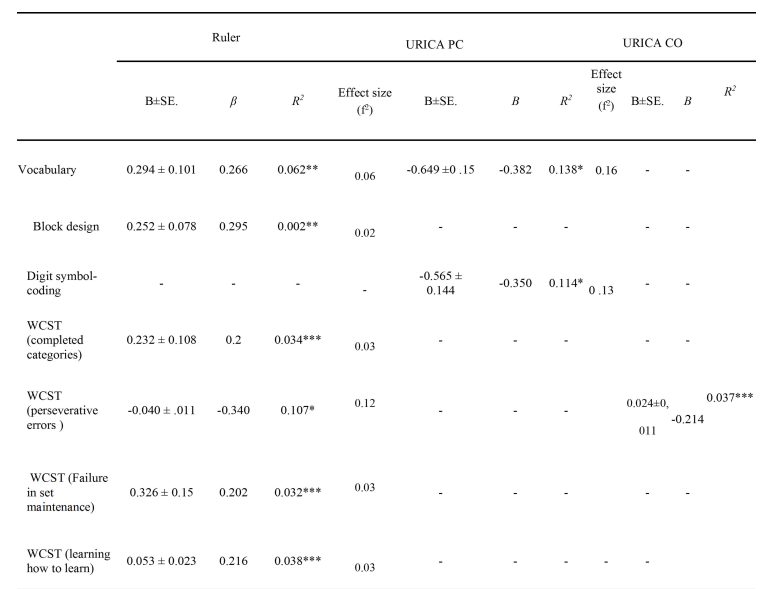

$$
\begin{gathered}
\text { Note: } \mathrm{B}=\text { Regression coefficient; } \mathrm{SE}=\text { Standard } \\
\text { error; } \beta=\text { Weighted regression coefficient; } \mathrm{R}^{2} \\
=\text { Percentage of variance explanation; } *= \\
\mathrm{p} \leq 0.001 ; * *=\mathrm{p} \leq 0.01 ; * *=\mathrm{p} \leq 0.05 . \text { Effect size } \\
\left(\mathrm{f}^{2}\right)=\text { small }(0.2), \text { medium }(0.15) \text {, large }(0.35) \\
\text { Cohen's classification (Wuensch, April } 42017) \\
\text { Source: own work. }
\end{gathered}
$$

\section{Discussion}

Changing addictive behavioral patterns requires the full awareness of the damages caused by the drug abuse as well as the ability to identify risky situations and to avoid relapses. In that sense, preserving cognitive functions such as attention, memory, and cognitive flexibility are necessary to help individuals throughout the changing processes towards quitting addictive behaviors (Prochaska, \& DiClemente, 1982; Prochaska, DiClemente, \& Norcross, 1992).

In the pre-contemplative stage of motivation, the damage caused by the substance use isn't clearly perceived by the user. Thus, behaviors related to the drug abuse are not a target of change. In our sample, about $33 \%$ of the participants were in the PC stage according to the URICA, and we found that low performances on the VOC and the SC tests predicted the PC stage in $13.8 \%$, and $11.4 \%$ respectively. These results suggest that long-term memory, attention, and processing speed deficits are contributing to the lack of motivation to change in this percentage of the sample. Our results follow the findings of a previous study (Blume et al., 2005) that yielded the same correlation between poor verbal and memory performance and the PC stage among alcoholics.

Our data also showed that performances on the WAIS-III VOC and BD subtests predicted the self-assigned readiness to change on the RCR. This finding reinforces the role of preservation of general verbal knowledge, planning, and processing speed skills over the self-reported level of motivation to change. The nature of the RCR instrument can help to address this finding. As an ideographic measure of motivation (Haynes, Mumma, \& Pinson, 2009), the RCR requires a metacognitive process based on the reflection about how much the problem is understood, how the subject views its intensity, and how strong is the subject's wiliness to change (Aharonovich, 2008; Velasquez et al., 2001). In that sense, cognitive resources such as language, memory, and processing speed, depending on their status, can either favor or ruin deeper analyses of the self and the environment, resulting in greater or lower motivation towards the changing process.

As the literature suggests, our participants also experienced difficulties in expressing EF, such as inhibitory control and cognitive flexibility, which we observed through their performance on the WCST. Succeeding on this task requires abilities related to sequencing, monitoring, and the flexibility to perceive and execute changes demanded by the environment. As the high scores of perseverative errors show, participants had a hard time in acknowledging the change in the rules and adequate their response accordingly to each trial. Our results showed positive correlations between scores on the CC, LHL, and FSM indexes of the WCST and the RCR, and a negative correlation between the latter and PE. It means that low levels of readiness to change according to the RCR, are related to low scores on CC, LHL, and FSM and high scores on $\mathrm{PE}$, indicating that a lack of mental flexibility is directly linked to low motivation to change. Rigoni et al. (2009) found a similar result with alcoholics, and Severston et al. (2010) had the same findings with heroin and cocaine users, 
reinforcing the idea of the correlation between failing on tasks that demand mental flexibility and readiness to change among substance users.

This paper aimed to verify to which extent cognitive performance is associated with and influences the readiness to change in cocaine/ crack users. Although we found statistically significant correlations between readiness to change and cognitive measures, they were mostly weak to moderate. Our regressions, exploring the cognitive measures as predictors of readiness to change, showed a limited range of influence. Even though the correlations were statistically significant, the major predictors accounted only for a little percentage of the variances, also producing small effect sizes. These results are partially due to the lack of homogeneity of the sample, an important limitation of the study. The sample used in this study was retrieved from a larger research, addressing the validation of a treatment protocol based on the TTM and Motivational Interviewing in Brazil. For this larger study, variables such as educational level and cognitive status were not exclusion criteria. Therefore, the sample for the present analysis was highly heterogeneous, with participants diverging significantly regarding period of abstinence, duration of drug consumption, education, and age. Those differences lead to means with high $\mathrm{SD}$ in all the investigated measures, limiting better results and more specific conclusions. It is possible that a more homogeneous sample in terms of cognition, education, age, and periods of abstinence would have provided more robust results concerning the relationship between cognitive tasks and motivational levels.

Despite the low accountability of the cognitive predictors over the motivational levels and the small effect sizes, evidence of statistically significant relationships among these variables does imply that neuropsychological functions are important factors to be considered in the motivation for treatment among substance users. Active neuropsychological rehabilitation targeting the improvement of abilities such as learning from the context, judgment, and decision-making, as well as capacity to inhibit automatic behaviors can help substance users to build cognitive resources, facilitating the path throughout the motivational stages.

More studies focused on the impact of cognition on motivation to change are needed to provide more comprehensive and objective data. The exploration of cognitive training is also necessary to verify the efficacy of neuropsychological rehabilitation to promote the maintenance and success of treatments targeting cocaine and crack users.

\section{Acknowledgements}

The first author was awarded with a $\mathrm{PhD}$ scholarship from CAPES (Coordination for the Improvement of Higher Education Personnel) that supported her work during this research. The second author was awarded with a DTI/ FAPERGS grant that supported her work regarding this research. Currently, the 2 nd author is supported by a fulltime $\mathrm{PhD}$ scholarship from the CNPQ/SWB program.

\section{References}

Abdalla, R.R., Madruga, C.S., Ribeiro, M., Pinsky, I., Caetano, R., \& Laranjeira, R. (2014). Prevalence of cocaine use in Brazil: data from the II Brazilian national alcohol and drugs survey (BNADS). Addict Behavior, 39(1), 297-301.

Aharonovich, E., Amrhein, P.C., Bisaga, A., Nunes, E.V., \& Hasin, D.S. (2008). Cognition, Commitment Language, and Behavioral Change Among CocaineDependent Patients. Psychology of Addictive Behaviors, 22(4), 557-562.

Ahmadi, J., Kampman, K.M., Oslin, D.M., Pettinati, H.M., Dackis, C., \& Sparkman, T. (2009). Predictors of treatment outcome in outpatient cocaine and alcohol dependence treatment. American Journal of Addiction, 18(1), 81-6.

Berry, J., Van Gorp, W. G., Herzberg, D. S., Hinkin, C., Boone, K., Steinman, L., \& Wilkins, J. N. (1993). Neuropsychological deficits in abstinent cocaine abusers: 
preliminary findings after two weeks of abstinence. Drug and Alcohol Dependence, $32(3), 231-237$.

Blume, A. W., Schmaling, K. B., \& Marlatt, G. A. (2005). Memory, executive cognitive function, and readiness to change drinking behavior. Addictive Behaviors, $30(2), 301-314$.

Boys, A., Marsden, J., \& Strang, J. (2001). Understanding reasons for drug use amongst young people: a functional perspective. Health Education Research, 16(4), 457-469.

Callegari-Jacques,S.M. (2005). Bioestatística: Princípio e Aplicações. Porto Alegre, RS: Artmed.

Compton, W. M., Thomas, Y. F., Stinson, F. S., \& Grant, B. F. (2007). Prevalence, correlates, disability, and comorbidity of DSM-IV drug abuse and dependence in the United States: results from the national epidemiologic survey on alcohol and related conditions. Archives of General Psychiatry, 64(5), 566-576.

Corsi, K. F., Kwiatkowski, C. F., \& Booth, R. E. (2007). Treatment entry and predictors among opiate-using injection drug users. The American Journal of Drug and Alcohol Abuse, 33(1), 121-127.

Cunha, P. J., Bechara, A., de Andrade, A. G., \& Nicastri, S. (2010). DecisionMaking Deficits Linked to Real-life Social Dysfunction in Crack Cocaine-Dependent Individuals. The American Journal on Addictions, 20(1), 78-86.

Cunha, P. J., Nicastri, S., Gomes, L. P., Moino, R. M., \& Peluso, M. A. (2004). Neuropsychological impairments in crack cocaine-dependent inpatients: preliminary findings. Revista Brasileira de Psiquiatria, 26(2), 103-106.

DiClemente, C. C., Schlundt, D., \& Gemmell, L. (2004). Readiness and stages of change in addiction treatment. American Journal of Addictions, 13(2), 103-119.

Fernandez-Serrano, M. J., Perez-Garcia, M., Perales, J. C., \& Verdejo-Garcia, A. (2010). Prevalence of executive dysfunction in cocaine, heroin and alcohol users enrolled in therapeutic communities. European Journal of Pharmacology, 626(1), 104-112.

Haynes, S. N., Mumma, G. H., \& Pinson, C. (2009). Idiographic assessment: Conceptual and psychometric foundations of individualized behavioral assessment. Clinical Psychology Review, 29(2), 179- 191.

Henderson, M. J., Saules, K. K., \& Galen, L. W. (2004). The predictive validity of the University of Rhode Island change assessment questionnaire in a heroinaddicted polysubstance abuse sample. Psychology of Addictive Behaviors, 18(2), 106-112.

Kjome, K. L., Lane, S. D., Schmitz, J. M., Green, C., Ma, L., Prasla, I., Swann, A. C., \& Moeller, F. G. (2010). Relationship between impulsivity and decision making in cocaine dependence. Psychiatry Research, 178(2), $299-304$.

Longshore, D., \& Teruya, C. (2006). Treatment motivation in drug users: A theory-based analysis. Drug and Alcohol Dependence, $81(2), 179-188$.

McConnaughy, E. A., Prochaska, J. O., \& Velicer, W. E. (1983). Stages of change in psychotherapy: measurement and sample profiles. Psychotherapy: Theory, Research and Practice, 20(3), 368-375.

Oliveira, M. S. (2010). Figuras complexas de Rey: Teste de cópia e de Reprodução de Memória de figuras geométricas complexas. Adaptação Brasileira. São Paulo: Casa do Psicólogo.

Prochaska, J. O., \& DiClemente, C. C. (1982). Transtheoretical therapy: Toward a more integrative model of change. Psychotherapy: Theory, Research and Practice, 19(3), 276-288.

Prochaska, J. O., DiClemente, C. C., \& Norcross, J. C. (1992). In search of how people change. Applications to addictive behaviors. American Psychologist, 47(9), 1102-1114.

Ratnasingham, S., Cairney, J., Rehm, J., Manson, H., \& Kurdyak, P.A. (2012). Opening Eyes, Opening Minds: The Ontario Burden of Mental Illness and Addictions Report. 
Ontario: An ICES/PHO Report. Toronto. Toronto: Institute for Clinical Evaluative Sciences and Public Health.

Rigoni, M. S., Oliveira, M. S., Susin, N., Sayago, C., \& Feldens, A. C. M. (2009). Prontidão para mudança e alterações das funções cognitivas em alcoolistas. Psicologia em Estudo, 14(4), 739-747.

Rodrigues, Horta, R. L., Szupszynski, K. P. R., Souza, M. C., \& Oliveira, M. S. (2013). Revisão sistemática sobre tratamentos psicológicos para problemas relacionados ao crack. Jornal Brasileiro de Psiquiatria, $62(3), 208-216$.

Severtson, S. G., von Thomsen, S., Hedden, S. L., \& Latimer, W. (2010). The association between executive functioning and motivation to enter treatment among regular users of heroin and/or cocaine in Baltimore, MD. Addictive Behaviors, 35(7), $717-720$.

Spronk, D. B., van Wel, J. H., Ramaekers, J. G., \& Verkes, R. J. (2013). Characterizing the cognitive effects of cocaine: A comprehensive review. Neuroscience and Biobehavioral Reviews, 37(8), 1838-1859.

Szupszynski, K. P. D. R., \& Oliveira, M. S. (2008). O Modelo Transteórico no tratamento da Dependência Química. Revista Psicologia: Teoria e Prática, 10(1), 162-173.

Velasquez, M., Maurer, G., Crouch, C., \& DiClemente, C. (2001). Group treatment for substance abuse: a stages-of-change therapy manual. New York: The Guilford Press.

Viola, T. W., Cardoso, C., Francke, I., Gonçalves, H., Pezzi, J., Araújo, R., Fonseca, R., \& Grassi-Oliveira, R. (2012). Tomada de decisão em dependentes de crack: um estudo com o Iowa Gambling Task. Estudos de Psicologia, 17(1), 99-106.

Wechsler, D. (1997). Wechsler Adult Intelligence Scale (3rd Edition). San Antonio, Texas: The Psychological Corporation.

Wuensch, K.L (2017, April 4). Standardized Effect Size Estimation: Why and How?. Retrieved from: http://core.ecu.edu/psyc/wuenschk/S tatHelp/Effect\%20Size\%20Estimation.pdf

\section{Notes}

* Research article. 